\title{
ANO 2030 - A AURORA DA PROFISSÃO DO MILÊNIO: \\ ENFERMAGEM - UMA VISÃO PROSPECTIVA DE ESTUDANTES DE \\ GRADUAÇÃO DE ENFERMAGEM ${ }^{1}$
}

\section{YEAR 2030: THE DAWN OF THE MILLENNIUM PROFESSION: NURSING - A PROSPECTIVE VISION OF UNDER-GRADUATE STUDENTS}

\author{
Taka Oguisso * \\ Jaqueline Correia Gaspar ** \\ Denise Sakura Kajimoto ** \\ Wendy Yamamoto **
}

OGUISSO T. et al. Ano 2030-A aurora da profissão do milênio: enfermagem-uma visão prospectiva de estudantes de graduação em enfermagem. Rev. Esc. Enf. USP, v. 33, n. 4, p. 384-90, dez. 1999.

Estudo sobre cartas-testamento escritas por estudantes do $1^{\circ}$ ano de graduação em enfermagem, que deveriam imaginar-se estar no ano 2030. Tudo o que esses alunos imaginaram que poderia ter acontecido nas três décadas anteriores a 2030 foi objeto dessa atividade, tais como conquistas profissionais e da profissão, cura de doenças, exercicio de cargos e prestigio social.

UNITERMOS: Prática profissional. Ocupações em saúde. Estudantes de Enfermagem.

LI:

Study based on testament-letters written by freshmen students of the undergraduate course in Nursing, who should imagine to be in the year 2030. Everything imagined by these students and that might have happened in the three earlier decades was the subject of this study, such as professional and nurses achievements, outbtreak of cure for illnesses, social prestige and positions.

UNITERMS: Professional practice. Health occupations. Students, nursing.

\section{INTRODUÇÃo}

O curso de graduação (BRASIL, 1994) da Escola de Enfermagem da Universidade de São Paulo (EEUSP), oferece no seu $1^{\circ}$ semestre letivo, dentro da área temática Fundamentos de Enfermagem, uma disciplina intitulada "ENO-101 Introdução à Enfermagem".

É uma disciplina de seis créditos-aula, desenvolvida em noventa horas de aulas teóricas e teórico-práticas, excluídas as horas reservadas às provas e visitas à instituições. Tem por objetivos:

- Instrumentalizar o aluno para a compreensão da Enfermagem como prática social;

- Relacionar os atuais modelos de prática de saúde e de Enfermagem à história dessas práticas;
- Compreender a Ética como ciência que norteia a inserção do cidadão e do profissional na sociedade;

- Compreender os processos de trabalho da Enfermagem nos âmbitos do cuidar individual, do cuidar coletivo e do administrar;

- Identificar as diversas realidades de saúde da população brasileira e as diferentes visões de saúde e doença subjacentes às políticas e programas de intervenção de saúde vigentes;

- Identificar as diferentes formas de inserção dos serviços de Enfermagem nas instituições de saúde e destas no Sistema Único de Saúde.

\footnotetext{
1 Trabalho baseado em cartas-testamento escritas por estudantes do $1^{\circ}$ ano de Graduação em Enfermagem da Escola de Enfermagem da Universidade de São Paulo, em março de 1998.

- Enfermeira e advogada. Docente da Escola de Enfermagem da Universidade de São Paulo.

* Alunas do $1^{\circ}$ ano do curso de Graduação em Enfermagem da Escola de Enfermagem da Universidade de São Paulo.
} 
No momento em que este trabalho foi elaborado, esta disciplina era lecionada por um grupo de sete docentes pertencentes a três dos quatro departamentos da EE-USP. A parte de história da Enfermagem, assim como seus aspectos éticos e legais, incluindo direitos humanos, Constituição e cidadania, direitos do paciente e entidades profissionais de Enfermagem foram ministradas em vinte e quatro horas de aula pela autora deste trabalho à turma do primeiro ano, no primeiro semestre de 1998.

Poder-se-ia prever que, por ser uma disciplina lecionada no primeiro semestre de um curso de graduação, o grupo que a assiste seria composto por estudantes recém egressados do curso colegial, ou que passaram um ou mais anos em cursos preparatórios ao vestibular. Entretanto, nesse grupo havia duas estudantes que já tinham exercido outra profissão de nível superior iniciado o terceiro grau em outras áreas antes de se decidirem pelo curso de Enfermagem. Vários destes estudantes reconheceram ter ingressado na carreira por acaso, pois buscavam uma profissão na qual pudessem "cuidar de gente" e ajudar as pessoas. Consideravam que a profissão que poderia lhes proporcionar isso seria a medicina, mas acabaram descobrindo que na enfermagem encontrariam campo para realizar esses ideais de maneira talvez até melhor, pela oportunidade de permanecer mais tempo junto às pessoas necessitadas de assistência, auxiliando-as na recuperação da saúde.

Esse grupo de maioria jovem, apesar de inexperiente em termos da profissão de Enfermagem, já percebia alguns dos problemas sociais sentidos pela classe. Para iniciá-los no exercício de reflexão a respeito da profissão que acabavam de escolher, foi-lhes solicitado, ainda na primeira semana de aulas do curso, em março de 1998, um exercício que consistia em entrevistar duas pessoas que não deveriam ser colegas ou pertencer ao corpo social da própria Escola de Enfermagem. Eles deveriam trazer por escrito as respostas obtidas a duas perguntas: "Como você vê o Enfermeiro?" e "O que você incluiria como atividade profissional cotidiana de um Enfermeiro, trabalhando em qualquer área (hospital, centro de saúde, etc.)?". O aluno foi instruído a reproduzir as expressões e adjetivos utilizados pelo seus respectivos entrevistados(as), que deveriam ser identificados(as) como parente ou amigo(a), sua respectiva profissão e faixa etária aproximada, citando se era jovem, adulto ou idoso.

Com as informações colhidas pelos calouros, em entrevistas com amigos da mesma faixa etária ou parentes adultos e idosos, foi elaborado um quadro em ordem decrescente de freqüência das respostas obtidas, cujos resultados foram discutidos com os alunos. Independentemente da profissão do entrevistado, constatou-se grande frequiência de respostas carregadas de preconceitos sociais, estigmas e opiniões negativas. $O$ enfermeiro ainda era percebido por muitos dos entrevistados como "auxiliar" ou "ajudante de médico", até mesmo como o "braço direito do médico". Por outro lado, a maioria das opiniões positivas veio carregada de expressões de doação ou adjetivos melífluos como "anjo da guarda", "anjo bom", "quase uma mãe", "profissão de doação", "humildade", "coragem e paciência" ou "pessoa dedicada". Da mesma forma, respostas que identificassem o enfermeiro como um profissional técnico, competente e portador de conhecimentos científicos não foram comuns. O físico CAPRA (1982) já reconhecia, que o pessoal de enfermagem, mesmo altamente qualificado, era considerado como mero auxiliar dos médicos e raramente podiam usar todo o seu potencial.

Esses dados, levantados pelos próprios estudantes nas entrevistas, e a discussão em classe sobre o passado histórico da enfermagem, com as lutas travadas pelas enfermeiras pioneiras para vencer os preconceitos sociais que sempre sombrearam a profissão, assim como as conquistas duramente alcançadas e os esforços dispendidos para tornar a profissão mais visível e valorizada pela sociedade, apontaram para a necessidade de marcar mais profundamente esses jovens, futuros profissionais, para abraçarem essa luta e assumirem sua parcela de responsabilidade nos destinos da carreira que escolheram.

George ORWELL (1977) escreveu na década de 70 o livro "1984", o qual antecipa muitos dos acontecimentos que vieram a se concretizar. Alvin TOFFLER (1971), descrevia em "o choque do futuro", a reação humana à carga de tensões, receios e ansiedades causadas no processo de adaptação às mudanças do futuro. Afirmava ele que "toda sociedade enfrenta, não apenas uma sucessão de futuros prováveis, mas um punhado de futuros possíveis e um conflito quanto aos futuros preferíveis; e, que a administração das mudanças consistia em despender esforço para converter certos possíveis em prováveis, em busca dos preferíveis. Em "Admirável mundo novo", Aldous HUXLEY (1982) escreve sobre uma sociedade utópica baseada em alta tecnologia e baixa complexidade, onde as máquinas são refinadas mas os relacionamentos sociais são fixos e simplificados.

No que se refere à enfermagem, há um relatório (não publicado) preparado pelo "INSTITUTE FOR ALTERNATIVE FUTURES" (1997) - uma instituição educacional e de pesquisa, sem finalidade lucrativa, fundada em 1977 em New York - para o Conselho Internacional de Enfermeiras (CIE) de Genebra, que convocou um Grupo de Trabalho em 1997 para tentar delinear um futuro desejável para a profissão.

No $2^{\circ}$ Congresso Europeu de Enfermagem, realizado em Amsterdã, Holanda, em outubro de 1997, foi apresentado um trabalho sobre os cenários previstos para a Enfermagem na Holanda, por BOEIJE et al (1977), da Universidade de Utrecht. Nesse trabalho, 
igualmente ainda não publicado, os autores descrevem o cenário da presente situação da sociedade, ou de partes desta, e das possíveis e desejáveis situações futuras. Entre as incertezas mais agudas na assistência de Enfermagem, na Holanda, foram citadas a emancipação do paciente e dos cuidadores informais (o que em nosso país seriam os atendentes de enfermagem, os agentes de saúde ou agentes comunitários). $\mathrm{Na}$ análise dos recursos foram mencionadas a interpretação de tarefas e a execução por enfermeiros e cuidadores no lar, assim como a restruturação e modernização da Enfermagem, do sistema de financiamento das casas de repouso (nursing homes) e dos cuidados domiciliares (home care).

Existem vários estudos e pesquisas para descrever o perfil de alunos ingressantes em cursos de enfermagem. Entre eles, podem ser citados o de ARCURI et al (1983) que publicaram um artigo sobre "os fatores que influenciaram alunos ingressantes na EE-USP, em 1981, na escolha da Enfermagem como opção profissional". Esses fatores seriam: o interesse pelas ciências biológicas, o desejo de ajudar pessoas e a preocupação com o nível de saúde da população.

HORTA et al (1988) realizaram um estudo comparativo, entre duas instituições de ensino, sobre as características e aspirações do graduando de Enfermagem. Não eram, porém, alunos ingressantes, mas veteranos de $5^{\circ}$ e $7^{\circ}$ período. Com pequenas variações, os estudantes de ambas instituições responderam buscar ascensão e crescimento profissional, assim como aquisição de conhecimentos e a satisfação do desejo de cuidar de pessoas como aspirações mais freqüentes.

Uma pesquisa exploratória sobre o perfil do aluno ingressante nos cursos superiores de enfermagem no Estado de São Paulo foi feita por TAVARES et al (1995) que aplicaram um questionário. Entre as perguntas havia uma referente aos aspectos importantes na escolha de um curso superior. As respostas encontradas foram relacionados com o mercado de trabalho e a remuneração $(18,8 \%)$, afinidade com a profissão $(18,4 \%)$ e o ideal, realização profissional e pessoal $(16,1 \%)$. As autoras concluiram que esses percentuais estavam aquém das expectativas para o desenvolvimento adequado no curso, mas $57,2 \%$ responderam também que estavam seguros de sua graduação no curso.

Porém, nenhum desses trabalhos traz a visão de estudantes sobre a profissão de enfermagem ou um exercício futurístico elaborado por eles. Daí o interesse em desenvolver esse estudo com a participação de alguns dos próprios calouros, membros da já citada turma de alunos de primeiro ano da EE-USP.

São objetivos deste estudo: divulgar os sonhos e desejos de futuros enfermeiros ainda no limiar de sua formação; identificar os valores e aspirações dos jovens ao iniciar a carreira de enfermagem; e, relatar uma experiência utilizada como estratégia de ensino em uma disciplina inicial do curso de graduação em enfermagem.
Além disso, com a realização desse trabalho, pretendeuse dar aos estudantes a oportunidade de participar na análise e interpretação de dados, na elaboração do relatório científico e na formação de atitudes éticas adequadas, além da aprendizagem decorrente da experiência de receber orientação direta em uma pesquisa desenvolvida junto com uma docente.

\section{MATERIAL E MÉTODO}

A totalidade dos estudantes do primeiro ano matriculados na disciplina "ENO-101-Introdução à Enfermagem" foi incluída neste estudo. Essa população era composta de 84 alunos, sendo apenas 5 do sexo masculino. A idade desses estudantes variava de 17 a 37 anos, mas a grande maioria situava-se entre os 19 a 22 anos. A maior parte deles procedia da cidade de São Paulo, embora alguns procedessem de cidades próximas ou de outros estados. Havia inclusive uma estudante de convênio, procedente do continente africano. Desse total, 72 estudantes estavam em classe quando foi solicitada a carta-testamento.

No dia 12 de março, ainda no decorrer da segunda semana de aulas da disciplina mencionada, os alunos foram solicitados a utilizar a última meia hora da aula para escrever uma carta - testamento, ou seja eles deveriam imaginar que estavam no dia 12 de março de 2030 , isto é, 32 anos adiante, quando muitos deles estariam maduros na profissão ou talvez até se preparando para a aposentadoria. Fazendo uma retrospectiva a partir de 2030 , deveriam tentar visualizar as grandes ou pequenas conquistas que a Enfermagem e seus profissionais teriam alcançado nas décadas anteriores e, então, redigir uma carta, com o formato de um testamento, para um neto(a) ou sobrinho(a), relatando como ele(a) próprio escolhera a "arte de cuidar" como profissão e, por fim, a recomendar ao seu destinatário. Os alunos não foram avisados antecipadamente sobre essa tarefa, pois a idéia era permitir que a imaginação fluísse livremente, sem balizamentos ou amarras que lhes delimitassem a criatividade.

O objetivo principal da tarefa era fazer os estudantes imaginarem o que poderia ser realizado no campo da enfermagem, para que posteriormente refletissem e batalhassem por aquela situação expressa nas cartas, tornando-se profissionais comprometidos com a profissão escolhida, ainda que ao acaso, em suma, desafía-los para que viessem a assumir a liderança da enfermagem no país.

A idéia dessa carta surgiu a partir de uma reunião ocorrida com um Grupo de Trabalho, organizada pelo CIE, em 1997, com enfermeiras líderes de vários países, representando todos os continentes, cujos objetivos eram: identificar as forças globais e as 
tendências que estavam impactando o futuro do setor saúde e da enfermagem; estabelecer uma visão do futuro desejado para esse setor e para a própria enfermagem, através de um processo participativo; e, desenvolver estratégias para alcançar as metas que levariam a esse porvir ansiado. Um profissional especializado (Robert Olson do "Instituto de Futuros Alternativos", dos EUA), foi convidado para coordenar essa reunião, onde discutiu-se que "o grande desafio realmente não é antecipar o futuro, mas construí-lo". A docente co-autora deste trabalho havia participado do citado Grupo de Trabalho no CIE, e estava convencida de que era possível construir ou criar esse futuro, se um grupo lutasse por fazê-lo acontecer.

Posto isso, foi solicitado aos calouros, em sua segunda semana de contato com a Escola, após terem vislumbrado alguns dos problemas profissionais durante a realização das mencionadas entrevistas, que visualizassem o que e como gostariam que a Enfermagem fosse, para que todos buscassem os próprios meios e caminhos lutando efetivamente por essas metas, pondo em prática hoje, o amanhã almejado.

Obtida a autorização unânime dos alunos, por escrito, para utilização do conteúdo dessas cartas para um trabalho a ser preparado para fins de publicação, foi aberta em classe, para todos os estudantes, a oportunidade de colaborar na análise e interpretação de dados, e na elaboração deste trabalho cientifico. As três alunas que se apresentaram são as co-autoras do presente estudo.

Cópias das "cartas-testamento" foram entregues a cada uma dessas alunas, para uma análise preliminar do conteúdo. Elas foram inicialmente orientadas quanto aos aspectos éticos do estudo, no sentido de que não deveriam tecer comentários positivos ou negativos sobre o conteúdo das cartas, principalmente na presença dos colegas, sobre como analisar o nucleo das mesmas, como classificar as idéias, palavras e expressões nelas contidas e como tabular os achados.

Diversas reuniões foram feitas com as alunas para identificar as expressões e termos valorativos sobre a profissão, utilizados pelos estudantes, para completar a classificação e para tentar elaborar tabelas ou gráficos. Verificou-se ser importante levantar a localidade onde se encontrava o aluno no momento de sua divagação, pois vários alunos, ao escrever a carta, imaginaram-se fora de São Paulo no ano 2030, citando cidades de repouso no interior do Estado, bem como outros estados e países.

\section{RESULTADOS}

Por não ter sido solicitada, nas instruções aos alunos, a identificação de um local específico onde estariam no ano 2030, no momento de redigir esta cartatestamento, 43 deles mencionaram São Paulo e 24 não fizeram referência a um local determinado. Porém, dois alunos citaram estar escrevendo de Londres e outros dois estariam no exterior, respectivamente Austrália e Estados Unidos, e três estariam em cidades ou estâncias no interior de São Paulo.

No texto da carta, trinta e dois alunos mencionaram haver realmente feito a sua primeira opção pela Enfermagem, mas treze não fizeram referência quanto a essa opção. Contudo, dezoito haviam optado pela Medicina, um pela Odontologia, um pela Veterinária, três haviam iniciado um outro curso superior, mudando posteriormente, e duas alunas cursavam a Enfermagem como um segundo curso superior.

As características profissionais da Enfermagem, na ótica dos estudantes, foram descritas com as seguintes expressões ou termos valorativos :

A profissão é muito mais do que cuidar do paciente... é mostrar que a vida vale a pena...

Acabei fascinada pela Enfermagem, uma carreira maravilhosa ...

Ajudar intensamente, numa relação sem nenhuma cobrança ...

A profissão me ensinou o que é o amor na totalidade...

Profissão que realmente engrandece a pessoa...

Profissão digníssima onde prevalece a solidariedade, há ênfase à vida e à dádiva de cuidar...

A profissão oferece o privilégio de cuidar de alguém, o que exige conciliar ciência com o dom de lidar com o próximo ...

Enfermagem: profissão brilhante, abrangente, emergente, independente ...

Profissão apaixonante, fascinante... (mencionada em várias cartas).

Profissão que é uma lição de amor, de vida e de dignidade...

Quantos momentos sagrados vivenciei na Enfermagem e isso foi o mais gratificante de tudo...

Profissão emocionante, nobre, indispensável, linda, humana , grandiosa ...

Profissão maravilhosa, de puro amor, que necessita de compaixão pelos outros $e$ paciência... 
A satisfação de poder ajudar e sentir-se útil é muito grande e compensa um agradecimento não recebido ...

Mas, um estudante alerta que um erro pode acabar com duas vidas: a do paciente e a sua vida profissional...

Outro estudante diz: Minha vida não teve grandes méritos não deixarei história, mas fui e sou feliz por ter ajudado o próximo ...

Quase todas as cartas mencionaram os preconceitos contra a profissão e/ou o profissional, que teriam existido em 1998, mas que estariam superados em 2030. Seis estudantes mencionaram problemas conflituais de preconceito social, seja deles mesmos ou de pais e amigos, mas que depois acabaram apaixonados pela profissão. Quase todos os estudantes citaram ter vencido os obstáculos (um deles escrevia que "sem obstáculos, não há superação") e que estavam orgulhosos da escolha feita na juventude . Uma estudante refere ter-se apaixonado pela Enfermagem antes mesmo de exercê-la e outra afirma que ser enfermeira é uma honra sem precedentes. Outra aluna recomenda a seu descendente que opte também pela profissão da suposta avó e que continue a luta pela enfermagem e que sinta sempre orgulho de ser Enfermeira (o). Outra confirma que a ciência $e$ tecnologia evoluem a cada dia, mas as pessoas nunca vão deixar de precisar umas das outras. Por isso, enfermeiras (os) são insubstituíveis. Apenas uma estudante cita a mudança do nome do profissional, de Enfermeiro para Enfermólogo, o que, segundo ela, teria contribuído para melhorar o reconhecimento da profissão.

Entre os progressos que teriam vivenciado, imaginaram a produção de carros que não poluem, a Floresta Amazônica sobrevivendo intacta e viagens à lua de forma corriqueira, de fácil acesso para a sociedade em geral. $\mathrm{Na}$ área da enfermagem, muitos deles mencionam o recebimento de prêmios pela dedicação à profissão ou pela participação em determinados projetos de pesquisa, que teriam contribuído para a melhoria dos níveis de saúde da população.

Há também menções da participação deles, especificamente, para que a profissão fosse mais visível pela sociedade e mais valorizada por ela, recebimento de convites para proferir conferências, ou ainda participação ativa na promoção de mudanças no conceito da enfermagem na sociedade, na luta e na conquista de altos cargos na hierarquia do país, como o de ministro da saúde, e assim garantir maior espaço para enfermeiros de gerações futuras, promovendo até a eleição destes para cargos legislativos como senadores, deputados e vereadores.
Outros referem, como conquistas, prosseguimento em carreira acadêmica com mestrado e doutorado em universidades; viagens ao exterior; estudos em outras áreas do saber, como sociologia e direito; a participação de enfermeiros em pesquisas para descoberta da cura de várias doenças, como AIDS e câncer; criação do prêmio Nobel de Enfermagem; padronização do ensino de enfermagem em nível técnico-científico (universitário) em todos os países do mundo; a equivalência numérica de profissionais do sexo masculino e feminino; o trabalho estaria facilitado com robôs e máquinas, apesar destes não substituírem os enfermeiros; a enfermagem tornara-se a carreira mais prestigiada na sociedade e o curso mais concorrido dos vestibulares.

Unanimemente, todos os estudante recomendavam a seus familiares da geração descendente que seguissem a carreira de enfermagem. Alguns escreveram estar deixando como herança seus bens patrimoniais ou depósitos bancários e livros publicados para seus descendentes, mas uma aluna escrevia singelamente deixar seu avental usado nas aulas de anatomia como lembrança, e outra que não tinha bens materiais a inventariar, mas que $a$ herança maior que deixava era a sua própria história de vida. Recomendava a seu descendente escolher a profissão com alma e coração e não com a conveniência ou ganância.

A maior satisfação que quinze estudantes teriam encontrado no exercício da enfermagem seria a oportunidade de ver um paciente curado de uma doença e poder devolvê-lo à sua família e comunidade, enquanto nove sentiriam essa satisfação ao colaborar no nascimento de uma criança.

As conquistas da profissão e dos profissionais nas três décadas anteriores ao ano 2030 , visualizadas pelos estudantes foram as seguintes: a enfermagem teria alcançado status social elevado; posicionamento de destaque na hierarquia das profissões de saúde; sucesso na cura de doenças como AIDS e câncer; melhor atendimento nos serviços de saúde para toda a população; competência legal para realizar anestesias e pequenas cirurgias, como já ocorre em muitos outros países; nível universitário para os cursos de Enfermagem no mundo todo; mudança do nome do profissional para Enfermólogo.

\section{DISCUSSÃo}

Alguns alunos mencionaram como conquistas de décadas anteriores ao ano 2030 atividades ou situações já existentes em 1998, mas certamente desconhecidos por eles por estarem em seus primeiros contatos com 0 curso de Enfermagem. Entre estas conquistas foram citadas: fazer parte da comissão de controle de infecção 
hospitalar e ingresso em curso superior sem exame vestibular previsto na Lei ${ }^{\circ}$ 9.394/96, de Diretrizes e Bases da Educação Nacional (BRASIL, 1996). Igualmente foi citada a equivalência salarial entre 0 médico e o enfermeiro porém, de acordo com a Lei $\mathrm{n}^{\circ}$ $3.780 / 60$, que reconheceu o nível técnico-científico do Enfermeiro no serviço público federal, todos os profissionais desse nível, inclusive médicos, dentistas e enfermeiros passaram teoricamente a receber salários iguais (BRASIL, 1960). Na prática, muitos desses profissionais não-enfermeiros cumpriam jornadas de trabalho inferiores aos de enfermeiros. Da mesma forma, docentes de categorias acadêmicas equivalentes nas universidades públicas recebem vencimentos básicos iguais.

Entre as supostas conquistas que teriam sido alcançadas, os alunos citaram também várias aspirações pessoais no campo político. Seis alunos identificaram-se como ministros da saúde ou notificaram seus descendentes que Enfermeiros já haviam ocupado essa posição. Entretanto, em alguns países da Europa (como Suécia e Islândia), do Oriente (Coréia do Sul - com a enfermeira Dra. Mo-Im Kim, senadora na década de 80 , Presidente do CIE de 1989-93, e, em abril de 1998, nomeada Ministra de Estado da Saúde) e mesmo da África (Angola, por duas vezes, na década de 70 e 80), enfermeiros já foram ministros da saúde. Outro cargo elevado citado na hierarquia hospitalar é a de diretor de hospital, e em muitos países já houve enfermeiros nessa posição e mesmo como diretores em coordenadorias hospitalares para todo o país (no caso do Brasil, com a enfermeira Clarice Ferrarini) ou de toda uma região sanitária. Os alunos não incluíram como aspiração um enfermeiro ocupar a posição de reitor em uma universidade brasileira, porque havia sido mencionado em aula que a enfermeira professora Milca Severino Pereira havia sido eleita reitora da Universidade Federal de Goiás, em 1998.

Evidentemente, recém ingressantes no curso de Enfermagem não poderiam saber desses fatos. Porém, os alunos citaram outros cargos políticos importantes ainda não ocupados por Enfermeiros, tais como o de diretor da Organização Mundial da Saúde (OMS). A partir de julho de 1998, pela primeira vez nos seus 50 anos desde sua fundação, essa Organização será dirigida por uma mulher, de origem norueguesa, médica, Gro Harlem Brundtland, que havia sido Primeira-Ministra de seu pais anteriormente, eleita em janeiro de 1998, pelo Conselho Executivo da OMS e referendada em maio do mesmo ano na Assembléia Mundial da Saúde.

Embora, no Brasil, ainda não tenha sido eleito um enfermeiro como senador da República, em outros países, como Coréia do Sul e Jamaica, já houve ou há enfermeiras nessa posição. Na Jamaica ela não foi apenas senadora, mas eleita também como presidente do senado. No Japão, há enfermeiras parlamentares nas duas casas legislativas (Dieta) e nos dois partidos mais importantes do país. Os britânicos, em sua "Câmara dos Lords" também contam com uma enfermeira. Nos EUA existem senadoras e deputadas enfermeiras eleitas no Congresso Nacional.

Outra aspiração citada foi o posicionamento de um enfermeiro como o Primeiro Mandatário do País, isto é, presidente da República, aspiração ainda não conquistada na maioria dos países. Entretanto, em Moçambique, o primeiro presidente da República foi Samora Machel, um enfermeiro que exerceu a profissão até começar a liderar as guerrilhas na luta para independência de seu país, que foi conquistada em 1975.

\section{CONSIDERAÇÕES FINAIS}

O conteúdo dessas "cartas-testamento" foi uma grande surpresa, pois havia cartas extremamente criativas e alentadoras, especialmente para enfermeiros e outros profissionais de enfermagem que, no seu dia a dia de trabalho, estão muitas vezes desanimados com o peso da rotina diária, desestimulados com a profissão, desalentados por falta de perspectivas e marcados pelos embates e desafios constantes na luta por melhores condições de trabalho.

Foi solicitada ao autor de uma dessas cartas, autorização para sua leitura em aula e, posteriormente, para a publicação* em sua forma original.

Verificou-se que a análise do conteúdo das outras cartas resultaria em excelente estímulo e alerta aos atuais enfermeiros, tanto aqueles que se encontram no exercício clínico, como aqueles que exercem a administração ou docência de enfermagem, sobre o que pensam os estudantes de hoje, profissionais de amanhã, e que perspectivas eles tem a respeito da profissão.

Estudantes que buscam a carreira de Enfermagem, seja por acaso ou como opção principal, são alunos provenientes de famílias inseridas num contexto social onde os valores, tais como status social e ganhos consideráveis, são muitas vezes determinantes na escolha da carreira ou profissão.

Contudo, segundo dados obtidos nessa população de ingressantes do curso de Enfermagem da Universidade de São Paulo, nem sempre os jovens escolhem a carreira apenas baseados nesses valores, mas pela vontade de "ajudar as pessoas" ou um ideal, dados esses que obtiveram grande freqüência (70\%) entre os estudantes em um trabalho realizado em 1981, por ARCURI et al.(1983). Em trabalho similar realizado por HORTA et al. (1988) e por TAVARES et al (1995) esses autores encontrarem também esse tipo de respostas entre as três mais frequentes. Nota-se, pois, que entre os jovens prevalece sempre o idealismo e o interesse de ajudar o próximo como um fator na escolha de uma profissão. Também se verificou que o 
sentimento de realização profissional, nesses alunos, provém muito mais de um sorriso tímido ou de um olhar encabulado de agradecimento, do sentimento do dever cumprido e de ter aliviado o sofrimento de alguém, do que de haver acumulado um patrimônio ao longo da vida.

Não há dúvidas que este é um grupo de jovens idealistas que ainda não sofreram os embates da vida ou da profissão, mas espera-se que os docentes e profissionais que forem encontrando no decorrer do curso ajudem a manter bem acesa a chama desse ideal, para que ao terminarem o curso de graduação eles possam orgulhosamente integrar a classe dos enfermeiros e engajar-se na luta para fazer acontecer esse futuro almejado e as aspirações manifestadas.

\section{REFERÊNCIAS BIBLIOGRÁFICAS}

ARCURI, E.A.M.et al. Fatores que influenciaram alunos ingressantes na Escola de Enfermagem da USP, em 1981, na escolha da enfermagem como opção profissional. Rev.Esc.Enf.USP, v. 17, n. 1, p. 5-19, 1983.

BOEIJE, H.R. et al. Future Scenarios for Nursing Congress on Enpowerment of the chronically ill: a challenge for nursing. 5-8 October 1997, Amsterdam, the Netherlands (not published).

BRASIL. Leis, etc. Lei n ${ }^{\circ} 3.780$, de 12 de julho de 1960 . Dispõe sobre a Classificação de Cargos do Serviço Civil do Poder Executivo, estabelece os vencimentos correspondentes e dá outras providências. Diário Oficial, Rio de Janeiro, 12 jul. 1960.
BRASIL. Leis, etc. Lei $n^{\circ} 9.394$, de 10 de dezembro de 1996 . Estabelece as diretrizes e bases da educação nacional. Diário Oficial da União, Brasília, 23 dez.1996. Atos do Poder Legislativo, Seção 1, v. 134, n. 248, p. 27833-27841.

BRASIL. Ministério da Educação e do Desporto. Portaria n. 1721 de 15 de dezembro de 1994. Dispõe sobre o curriculo mínimo de graduação em Enfermagem. Diário Oficial da União. Brasilia, 16 dez 1994. Seção 1, p. 19801-2.

CAPRA, F. O ponto de mutação. São Paulo, Cultrix, 1982. p. 150.

HORTA, A.L.M. et al. Características e aspirações do atual graduando de enfermagem - comparação entre duas instituições de ensino. Rev.Esc.Enf.USP, v. 22, n. 3, p. $323-37,1988$.

HUXLEY, A. Admirável mundo novo. São Paulo, Abril Cultural, 1982.

INSTITUTE FOR ALTERNATIVE FUTURES - Future directions - Report on Future Techniques for Nursing, Geneva, 1997 (not published)

ORWELL, G. 1984, Trad. de Wilson Velloso. São Paulo, Nacional, 1977.

TAVARES, M.S.G. et al. O perfil do aluno ingressante nos cursos superiores de enfermagem do Estado de São Paulo. Rev.Paul.Enf., v. 14, n. 2/3, p. 55-65, 1995.

TOFFLER, A. O choque do futuro. 3a. ed, Rio de Janeiro, Artenova, 1973. p. 384. 